\title{
Telomeric 22 q 13 deletions resulting from rings, simple deletions, and translocations: cytogenetic, molecular, and clinical analyses of 32 new observations
}

\author{
J J Luciani, P de Mas, D Depetris, C Mignon-Ravix, A Bottani, M Prieur, P Jonveaux, A Philippe, \\ G Bourrovillou, B de Martinville, B Delobel, L Vallee, M-F Croquette, M-G Mattei
}

J Med Genet 2003;40:690-696

T he terminal regions of human chromosomes are known to contain specialised DNA sequences and may be vulnerable to rearrangements causing human genetic diseases and particularly idiopathic mental impairment. ${ }^{12}$ During the last decade, there have been several reports of patients who are described as having a 22q13 monosomy resulting from simple terminal deletions. ${ }^{1-11}$ A common phenotype emerged from these reports, including variable learning difficulties with disproportionate verbal delay, generalised hypotonia, normal to accelerated growth, and minor facial dysmorphy. ${ }^{10}$ Monosomies for $22 \mathrm{q} 13$ have also been reported that result from unbalanced translocation with an acrocentric short arm. ${ }^{10}{ }^{12}$ The acrocentric short arms only bear ribosomal genes, and their duplication or deletion is not generally thought to be phenotypically significant. Therefore such translocations can be considered as "pure" terminal $22 \mathrm{q} 13$ deletions.

A distinct group of 22q13 monosomies has been reported that result from the formation of a ring chromosome which combines loss of some long arm material with loss of part of the short arm, with no clinical consequences. Nevertheless, although ring chromosome 22 has been described in over 50 cases ${ }_{13}^{13}$ it remains uncertain whether the variable phenotype is caused by the loss of a variable amount of chromosomal material or by a cellular mosaicism arising from instability of the ring.

Regardless of the causative rearrangement, very few cases of "pure" 22q13 monosomy have been investigated up to now by detailed molecular studies. In order to characterise this syndrome better, facilitate the diagnosis, and provide targeted health care for affected individuals, we have studied 33 patients (32 new observations) with a pure 22q13 partial monosomy, using molecular and cytogenetic methods.

\section{METHODS \\ Subjects}

Our study involved 33 patients with a "pure" partial 22q13 monosomy, with exclusion of all rearrangements involving loss or gain of euchromatic material from any other chromosome than number 22 . There were 17 patients with an $\mathrm{r}(22)$ chromosome (cases 1 to 17 ), one of whom has already been reported (case $2^{14}$ ). Twelve patients had a simple terminal 22q13 deletion (cases 18 to 29). Four patients had an unbalanced translocation involving an acrocentric short arm (cases 30 to 33) and were considered as "pure" 22q13 monosomies. Among these translocations, one (case 30) resulted from the malsegregation of a balanced paternal translocation and the karyotype was 46,XX,der(22) $\mathrm{t}(14 ; 22)(\mathrm{pl}$; q 13$)$ pat; two (cases 31 and 33) were de novo translocations involving the $22 \mathrm{q} 13$ band and the short arm of an unidentified acrocentric, with the karyotype 46,XX, $\operatorname{der}(22) \mathrm{t}(22 ; \mathrm{acro})(\mathrm{q} 13 ; \mathrm{pl} 1)$. Case 32 was a de novo tandem

\section{Key points}

- This is the most extensive study to date of patients with telomeric $22 \mathrm{q} 13$ monosomy, including ring chromosomes, simple 22q13 deletions, and unbalanced translocations with an acrocentric short arm.

- The deletions were shown to be extremely variable in size, extending from $160 \mathrm{~kb}$ to $9 \mathrm{Mb}$, and their parental origin was much more often of paternal (74\%) than maternal origin (26\%).

- Phenotype-genotype correlations showed no gross phenotypic differences between the 22q13 deletion and the $r(22)$ syndromes for similar sized deletions. Nevertheless, behavioural disorders were a constant feature and increase in severity with age. Although patients with simple $22 \mathrm{q} 13$ terminal deletion had a general tendency to overgrowth, the $r(22)$ patients often showed growth failure.

- This is the largest series of patients to have been molecularly characterised and includes the $r(22)$ patient with the smallest deletion described to date. The minimum critical region responsible for the monosomy 22q13 phenotype includes the genes PROSAP2/SHANK3, $A C R$, and RABL2B, but not ARSA.

translocation involving the $22 \mathrm{q} 13$ band and the short arm of a chromosome 15, with the karyotype 45,XY,-22,-15, + der $(22$ pter $\rightarrow 22$ q13::15pl2 $\rightarrow$ 15qter $)$.

Clinical examination of the patients was undertaken using the same criteria for all. The parents were interviewed with a standard questionnaire about their child's development and behaviour, and the resulting data were used to assess the child's disability. For all patients, pregnancy and birth data showed no remarkable events. The age and sex of the patients are reported in table 1 , as well as the main clinical signs scored for degree of severity $(+,++,+++)$.

\section{Procedures}

Metaphase spreads from the patients were prepared according to standard procedures and at least 50 metaphases were analysed for each of them, in order to detect any mosaicism. Characterisation of the deleted material was done by fluorescence in situ hybridisation (FISH) using BAC and PAC clones obtained from the Sanger Institute (www.sanger. ac.uk), and cosmid clones from Invitrogen (Invitrogen-Life Technologies, Cergy-Pontoise, France). All these probes, for which the relative order was determined by searching in 
Table 1 Main clinical signs of 33 patients with 22q13 partial monosomy

\begin{tabular}{|c|c|c|c|c|c|c|c|c|c|c|c|}
\hline \multicolumn{2}{|l|}{ Patients } & \multirow{2}{*}{$\begin{array}{l}\text { Age }(y) \\
20\end{array}$} & \multirow{2}{*}{$\begin{array}{l}\text { Sex } \\
M\end{array}$} & \multirow{2}{*}{$\begin{array}{l}\text { Hypotonia } \\
+\end{array}$} & \multirow{2}{*}{$\begin{array}{l}\begin{array}{l}\text { Global } \\
\text { development } \\
\text { delay }\end{array} \\
+\end{array}$} & \multirow{2}{*}{$\begin{array}{l}\text { Speech } \\
\text { delay }\end{array}$} & \multirow{2}{*}{$\begin{array}{l}\text { Growth } \\
\text { (N,A,D) }\end{array}$} & \multirow{2}{*}{$\begin{array}{l}\text { Dysplasic } \\
\text { ears }\end{array}$} & \multirow{2}{*}{$\begin{array}{l}\text { Seizures } \\
-\end{array}$} & \multirow{2}{*}{$\begin{array}{l}\text { Behavioural } \\
\text { disorders }\end{array}$} & \multirow{2}{*}{$\begin{array}{l}\text { Size } \\
\text { (Mb) }\end{array}$} \\
\hline$r(22)$ & 1 & & & & & & & & & & \\
\hline & 2 & 10 & M & - & + & + & $\mathrm{N}$ & + & - & ++ & 0.31 \\
\hline & 3 & 14 & M & - & + & +++ & $\mathrm{N}$ & + & - & +++ & 0.31 \\
\hline & 4 & 26 & $\mathrm{~F}$ & + & + & + & $\mathrm{N}$ & + & ++ & +++ & 0.9 \\
\hline & 5 & 6 & $\mathrm{~F}$ & + & + & ++ & $\mathrm{N}$ & + & - & ++ & 0.9 \\
\hline & 6 & 16 & M & + & + & ++ & D & + & + & +++ & 1.6 \\
\hline & 7 & 7 & $M$ & + & ++ & +++ & $\mathrm{N}$ & - & - & + & 1.6 \\
\hline & 8 & 1 & $\mathrm{~F}$ & + & $+/-$ & nd & D & + & - & - & 1.72 \\
\hline & 9 & 20 & M & - & + & ++ & $\mathrm{N}$ & + & - & +++ & 2.3 \\
\hline & 10 & 36 & $\mathrm{~F}$ & + & + & + & $\mathrm{N}$ & + & - & +++ & 2.3 \\
\hline & 11 & 9 & M & - & + & ++ & $\mathrm{N}$ & + & - & ++ & 2.3 \\
\hline & 12 & 34 & $\mathrm{~F}$ & + & ++ & +++ & $\mathrm{N}$ & + & + & +++ & 3.09 \\
\hline & 13 & 27 & M & + & ++ & +++ & $\mathrm{N}$ & + & - & +++ & 3.09 \\
\hline & 14 & 12 & $\mathrm{~F}$ & + & ++ & + & $\mathrm{N}$ & + & - & ++ & 3.09 \\
\hline & 15 & 16 & M & + & ++ & +++ & $\mathrm{N}$ & + & - & ++ & 5.6 \\
\hline & 16 & 3 & $\mathrm{~F}$ & + & +H+ & ++ & D & + & - & + & 5.8 \\
\hline & 17 & 3 & M & + & ++ & ++ & $\mathrm{N}$ & + & - & + & 5.8 \\
\hline \multirow[t]{12}{*}{ del(22) } & 18 & 6 & $\mathrm{~F}$ & - & $+1-$ & ++ & $\mathrm{N}$ & - & - & + & 0.16 \\
\hline & 19 & 4 & $\mathrm{~F}$ & + & + & ++ & $\mathrm{N}$ & - & - & ++ & 0.31 \\
\hline & 20 & 16 & $\mathrm{~F}$ & + & + & ++ & $\mathrm{N}$ & - & - & +++ & 0.31 \\
\hline & 21 & 3 & $\mathrm{~F}$ & ++ & +H+ & + & A & + & - & + & 5.8 \\
\hline & 22 & 12 & $\mathrm{~F}$ & + & ++ & +++ & $\mathrm{N}$ & + & + & ++ & 5.8 \\
\hline & 23 & 14 & $\mathrm{~F}$ & + & +H+ & +++ & A & + & - & ++ & 5.8 \\
\hline & 24 & 3 & M & + & +H+ & ++ & A & + & - & + & 5.85 \\
\hline & 25 & 15 & M & + & +H+ & +H+ & $\mathrm{N}$ & + & + & $+1-$ & 7.2 \\
\hline & 26 & 6 & $\mathrm{~F}$ & + & +H+ & +H & $\mathrm{N}$ & + & + & $+1-$ & 7.2 \\
\hline & 27 & 6 & $\mathrm{~F}$ & + & +H+ & +H & $\mathrm{N}$ & + & + & $+1-$ & 7.2 \\
\hline & 28 & 4 & M & + & +H+ & +H & A & + & - & + & 8.9 \\
\hline & 29 & 13 & $M$ & + & ++ & ++ & A & + & - & $+/-$ & 8.9 \\
\hline \multirow[t]{4}{*}{$\dagger(22)$} & 30 & 9 & $\mathrm{~F}$ & + & + & +++ & $\mathrm{N}$ & + & - & + & 0.31 \\
\hline & 31 & 29 & $\mathrm{~F}$ & - & + & ++ & $\mathrm{N}$ & - & - & +++ & 0.31 \\
\hline & 32 & 8 & $M$ & + & + & ++ & A & + & ++ & ++ & 3.9 \\
\hline & 33 & 2.5 & $M$ & + & ++ & + & $\mathrm{N}$ & + & - & + & 5.8 \\
\hline
\end{tabular}

$\mathrm{F}$, female; $\mathrm{M}$, male; nd, not determined; $\mathrm{N}$, normal; $\mathrm{A}$, accelerated; $\mathrm{D}$, delayed growth.

- feature absent; + feature present; ++ severe; +++ very severe.

"ensembl genome browser" (www.ensembl.org) and in "UCSC genome browser" (wwww.genome.ucsc.edu), are shown in fig 1 . They were, from centromere to telomere, RP4-753M9, RP5-996D20, RP11-191L9, RP11-536P6, RP11255N20, RP5-1061018, RP11-494O16, RP4-579N16, CTA384D8, and cosmids LL22NCO3-n66c4, -n85a3, -n94h12, -nlg3. The BAC CTA-357F7, containing the "cat eye syndrome" locus, ${ }^{15}$ was differentially labelled and co-hybridised with each telomeric probe, in order to identify both chromosomes 22 unambiguously during metaphase.
To elucidate the mechanisms involved in the formation of the rearranged chromosomes 22, three specific probes were used: a synthetic peptide nucleic acid PNA-(CCCTAA) 3 oligonucleotide probe ${ }^{16}$ for detecting consensus telomeric TTAGGG repeats; a $\beta$ satellite probe (Oncor P5096), to define the $22 \mathrm{p}$ breakpoint on the ring chromosomes; and a $5.8 \mathrm{~kb}$ probe, ${ }^{17}$ to detect ribosomal DNA sequences in the ring chromosomes. All the probes were labelled by random priming with either biotin-14dCTP (Bioprime DNA labelling system, Life Technologies) or digoxygenin-1ldUTP (High
A

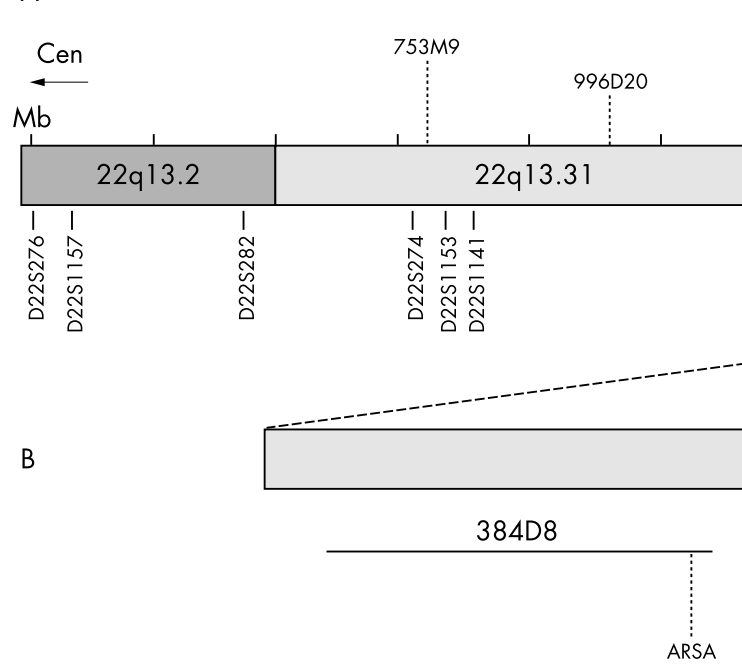

Tel Figure 1 Ideogram of the distal 22 q13.3 band of chromosome 22 long arm: (A) Respective location of the FISH probes (above), and the microsatellite markers (below) used in this study. (B) Enlargement of the most telomeric part of this region allowing the cosmids contig to be located with respect to BAC 384D8 and the genes they contain. Cen, centromere; Tel, telomere; $\mathrm{Mb}$, Megabase. 


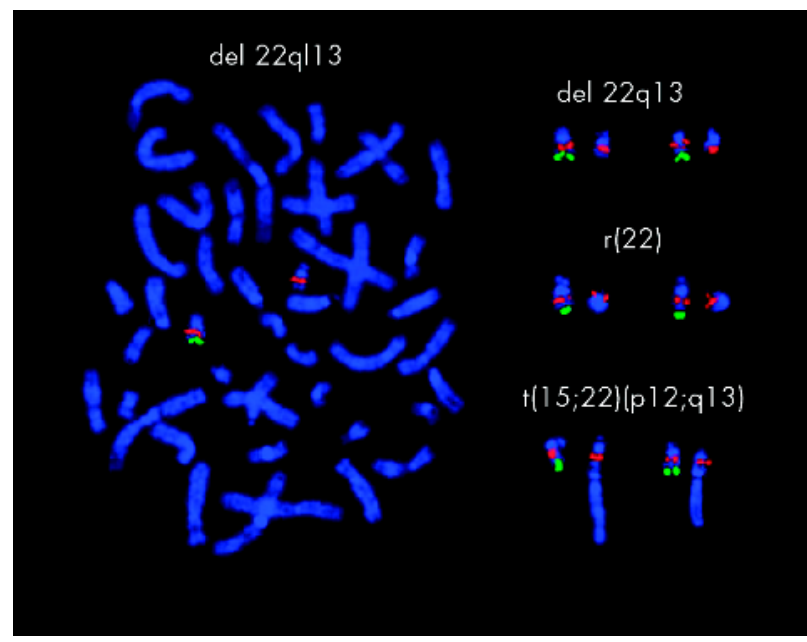

Figure 2 Determining the size of the deletion using dual colour FISH on metaphases of patients with 22q13 partial monosomy. Left: the entire metaphase of a patient with simple 22q13 deletion. Right: chromosomes 22 from patients with a simple deletion (top), a r(22) (middle), and a translocation (case 32) (bottom). The red signals correspond to BAC $357 F 7$ which is juxta-centromeric on chromosome 22. The green signals correspond to the BAC 384D8, telomeric. Chromosomes are counterstained in blue with DAPI.

prime, Roche diagnostics, Meylan, France), hybridised to metaphase chromosomes and revealed using standard protocols. Commercial probes were used as recommended in the manufacturers' protocols.

The parental origin of 32 deletions was studied by microsatellite analysis (parents of patient 31 were unavailable). DNA from patients and their parents was extracted by standard methods. The DNAs were typed with 14 polymorphic microsatellite repeats mapped to the $22 \mathrm{q} 13$ region (fig 1). There were eight Genethon STR markers (D22S276, D22S1157, D22S282, D22S274, D22S1153, D22S1141, D22S1161, D22S1169) and six new markers (3GT, 4CA, 6CA, 1CA, 8GT, 7CT) which we designed using the following bio-informatic programs: "Tandem repeat finder" (www.c3. biomath.mssm.edu/trf.html), "Geneworks" (IntelliGenetics Inc, Oxford Molecular SA, Palaiseau, France), "Primer3" (www.genome.wi.mit.edu/cgibin/primer/primer3.cgi/), and NCBI BLAST (www.ncbi.nlm.nih.gov). All couples of primers used in this study were obtained from MWG-Biotech AG (mwg-biotech.fr), with one primer per couple carrying a $5^{\prime}$ IRD 800 label. Polymerase chain reactions (PCR) were undertaken on genomic DNA with a commercial kit including Taq DNA polymerase, incubation buffer, and $\mathrm{MgCl}_{2}$ (QBIOgene). Different annealing temperatures were tested for each couple of primers in order to obtain optimal amplification. Allelic inheritance was then visualised by electrophoretic migration of PCR products using polyacrylamide sequence gel and an automated sequencer (LiCor 4200).

\section{RESULTS}

\section{Characterisation of the deletions by FISH analysis}

In the $r(22)$ patients, two breakpoints are expected to have produced the ring-one on the short arm, the other on the long arm. The most distal long arm breakpoint (case 1) was distal to BAC 384D8 (figs 2 and 3) and corresponds to the smallest deletion (about $160 \mathrm{~kb}$ according to "UCSC genome browser"). The most proximal long arm breakpoints were centromeric to PAC 753M9 and delineate deletions larger than $5.8 \mathrm{Mb}$ (cases 16 and 17). These results showed the deleted segments to be of variable size within the $22 \mathrm{q} 13.3$ terminal band. In addition, we did not observe any telomeric repeat on the ring chromosomes using the specific probe PNA-(CCCTAA $)_{3}$ (data not shown). We have located the short arm breakpoints either to $22 \mathrm{pll}$ (15/17 cases)-a region known to be enriched in satellite DNA-or to $22 \mathrm{pl} 2$ containing the rDNA (2/17 cases). Dual colour FISH with the BAC 357F7 probe showed the degree of mosaicism to be very low, and nearly all $\mathrm{r}(22)$ patients had one copy of the ring in the large majority of the metaphases analysed (98\% to 100\%). Complete monosomy 22 and dicentric or pulverised rings were extremely rare $(0 \%$ to $2 \%)$, suggesting that rings of chromosome 22 are remarkably stable. However, one patient (case 1) was different from the others, having $8 \%$ of cells with dicentric and pulverised $\mathrm{r}(22)$ and $2 \%$ of cells with loss of the ring. Despite the remarkable stability seen in metaphase for all patients, micronuclei were observed. These most often contained the ring chromosome 22, as demonstrated by dual colour FISH (data not shown).

In our series of 12 simple 22q13 deletions (figs 2 and 3), the large majority of deletion breakpoints (8/12) appeared to be located in the region proximal to PAC $753 \mathrm{M} 9$ and correspond to deletions larger than $5.8 \mathrm{Mb}$. The smallest deletion (case 18) resulted in the loss of only $160 \mathrm{~kb}$ from 22q. The apparent non-homogeneous distribution of breakpoints in simple 22q13 deletions could result from a failure to detect small size deletions using standard or high resolution cytogenetics. It should be noted that large deletions from this sample had all been primarily identified by standard cytogenetics, which may have introduced a bias favouring the more visible deletions. In contrast, the smallest deletions (cases 18, 19, and 20) had been primarily identified by FISH.

Among the four patients with an unbalanced translocation, three (cases 30, 31, and 33) had 46 chromosomes, with the deleted chromosome 22 showing two $\beta$ satellite fluorescent signals (data not shown)-one located normally on the short arm and the other at the end of the long arm. The fourth patient (case 32) had only 45 chromosomes, with an entire chromosome 15 translocated in tandem onto the distal 22q13 band of one chromosome 22 (fig 2 ). The $\beta$ satellite probe showed a positive signal close to the junction of the translocation, suggesting that the short arm of the translocated chromosome 15 was retained. Though involving a smaller number of cases, the breakpoints appear to be distributed similarly to those observed in the cases of ring chromosome 22 (fig 3).

Finally, taking into account the possible bias in the simple $22 \mathrm{q} 13$ deletion sample, our results indicated that whatever the rearrangement involved, the deletions were extremely variable in size. We estimate their extents to range from $160 \mathrm{~kb}$ to $9 \mathrm{Mb}$, according to marker positions determined from an integrated map of the genome. Interestingly, several patients (cases 2, 3, 19, 20, 30, and 31) had a deletion breakpoint located between BAC 494016 and PAC 579N16. In order to define this breakpoint, three PACs located in this interval-RP3-355C18, RP5-898 I 4, and RP3-402G11 (Sanger Institute)-were hybridised to patients' metaphases. Five patients (cases 2, 3, 19, 30, and 31) were shown to share the same breakpoint located between PACs 402G11 and 579N16, a distance of $100 \mathrm{~kb}$. This small interval has not yet been sequenced and corresponds to a gap. ${ }^{18}$

\section{Parental origin of the deletions determined by microsatellite analysis}

The parental origin of 32 deletions was evaluated by microsatellite analysis in order to determine a possible parent-of-origin effect on the phenotype. Not all patients could be tested for parental origin using Genethon microsatellite markers because the most distal one, D22S1169, was excluded from the smaller deletions. The six microsatellite 


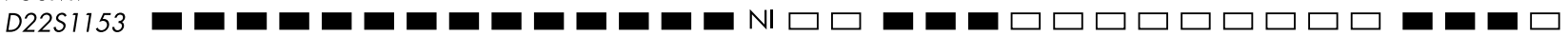

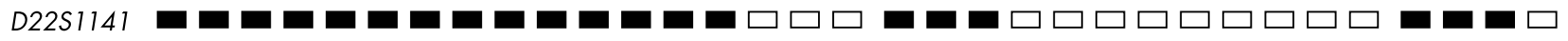

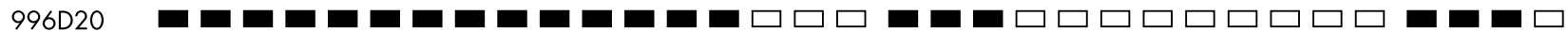

19119

$536 \mathrm{P6}$

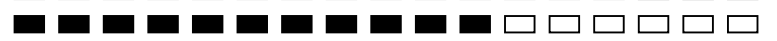

घロ $\square \square \square \square \square \square \square \square \square$

$\square \square \square$

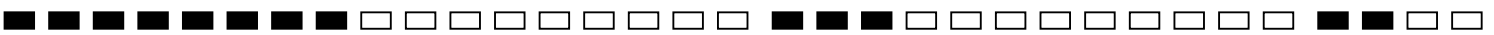

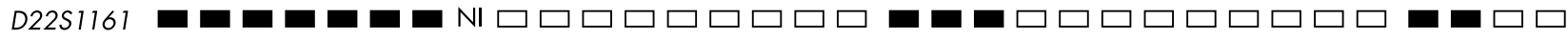

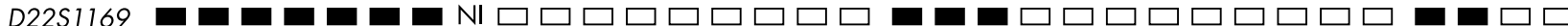

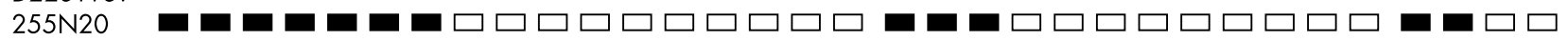

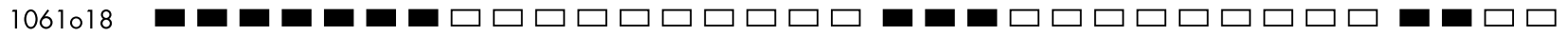

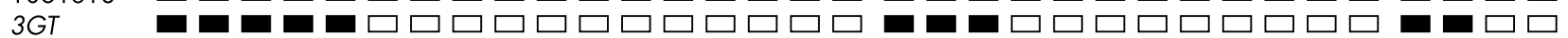
$4 C A$ m ש m NI $\square \square \square \square \square \square \square \square \square \square \square \square$

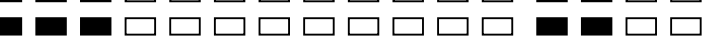

6CA2

494016

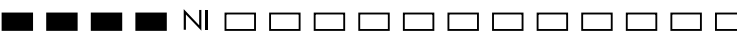
घ $\boldsymbol{\square} \square \square \square \square \square \square \square \square \square \square \square \square \square \square$

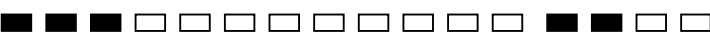
579N16 $\square \square \square \square \square \square \square \square \square \square \square \square \square \square \square \square \square \square \square \square \square \square \square \square \square \square \square \square \square \square \square \square \square$ // ICA $\square \square \square \square \square \square \square \square \square \square \square \square \square \square \square \square \square \square \square \square \square \square \square \square \square \square \square \square \square \square \square \square \square$ $384 \mathrm{D} 8$

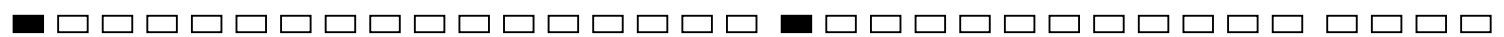
$/ / 7 C T$ $/ / 8 G T$

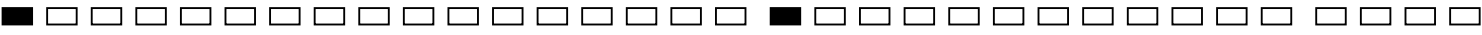

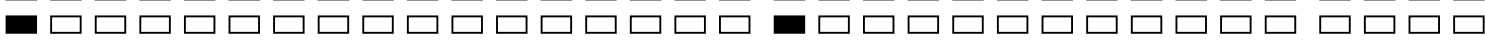
$\cos 66 \mathrm{c4} \square \square \square \square \square \square \square \square \square \square \square \square \square \square \square \square \square \square \square \square \square \square \square \square \square \square \square \square \square \square \square \square \square$ $\cos 85 \mathrm{a3} \quad \square \square \square \square \square \square \square \square \square \square \square \square \square \square \square \square \square \square \square \square \square \square \square \square \square \square \square \square \square \square \square \square \square$ $\cos 94 \mathrm{bl2} \square \square \square \square \square \square \square \square \square \square \square \square \square \square \square \square \square \square \square \square \square \square \square \square \square \square \square \square \square \square \square \square \square$ cos lg3 $\square \square \square \square \square \square \square \square \square \square \square \square \square \square \square \square \square \square \square \square \square \square \square \square \square \square \square \square \square \square \square \square \square$ Parent.Origin

$$
\begin{array}{lllllllllllllllllll}
P & P & P & P & P & P & M & M & P & P & M & P & P & P
\end{array}
$$

Figure 3 Determining the extent of the deletion in 33 patients with $22 q 13$ partial monosomy. The different cases from this study have been grouped with respect to the type of deletion: $r(22)$ : cases 1 to 17; simple del 22q13 deletions: cases 18 to 29 ; and translocations $\mathrm{t}(22)$ : cases 30 to 33 . For each type of anomaly, cases are ordered based on the size of the deletion, smallest to largest. In the left column are listed the FISH clones (bold) and the microsatellite markers (italic), ordered from centromere (CEN) to telomere. The sign // placed before a marker means it is included in the above FISH clone. "NI" means non-informative marker. The deleted loci are represented by white squares, the non-deleted ones by dark squares. The parental origin of each rearrangement in the last line: $M$, maternal origin; $P$, paternal origin; $(-)$, inconclusive analysis.

markers that we designed were located in a more distal region of chromosome 22 long arm (fig 1). Markers 3GT, 4CA, and 6CA were located between PAC 1061018 and BAC 494016; marker 1CA was included in the PAC 579N16; and markers 7CT and 8GT were included in the BAC 384D8. Finally, the parental origin of the rearranged chromosome was determined in 27 of 32 patients (fig 3), microsatellite analysis remaining inconclusive in cryptic deletions (cases 1 , 2, 3, 18, and 19). Among all 27 informative cases, the origin of the deletion was found to be paternal in $74 \%$ of patients and maternal in only $26 \%$ of patients (table 2 ). There was an evident excess of deletions of paternal origin and, interestingly, this paternal/maternal discrepancy seems to be more frequent in rearrangements with small size deletion (fig 3). In addition, patients with deletions of equivalent size were compared and showed no evident phenotypic differences,

Table 2 Parental origin of the deletion in $22 q 13$ partial monosomies

\begin{tabular}{llll}
\hline $\begin{array}{l}\text { Chr 22 } \\
\text { anomaly }\end{array}$ & $\begin{array}{l}\text { Informative } \\
\text { cases nb }\end{array}$ & $\begin{array}{l}\text { Paternal origin } \\
\text { nb (\%) }\end{array}$ & $\begin{array}{l}\text { Maternal origin } \\
\text { nb (\%) }\end{array}$ \\
\hline$r(22)$ & 14 & $11(78.6 \%)$ & $3(21.4 \%)$ \\
del (22) & 10 & $6(60 \%)$ & $4(40 \%)$ \\
$t(22)$ & 3 & $3(100 \%)$ & $0(0 \%)$ \\
Total & 27 & $20(74 \%)$ & $7(26 \%)$ \\
\hline
\end{tabular}

$\mathrm{nb}$, number of cases regardless of whether the deletion was of paternal or maternal origin. This indicates there is no parent-of-origin effect as regards the severity of the phenotype associated with $22 \mathrm{q} 13$ deletions-in agreement with the non-imprinted status of human chromosome 22. ${ }^{19} 20$

\section{Phenotype-genotype correlations}

In table 1 we summarise the clinical features observed most often in our series. These include hypotonia, global developmental delay, expressive speech delay, prominent or dysplasic ears, and behavioural disorders. Although these clinical signs are rather non-specific, the presence of other clinical findings has been observed by us and others to be extremely variable. ${ }^{4}$ Patients are classified in increasing order of deletion size for each type of rearrangement. In the last column of table 1 we report the approximate size (in megabases) of the deletions, in order to facilitate phenotype-genotype comparisons.

Hypotonia, most often acquired rather than neonatal, was present in 27 of 33 patients $(82 \%)$. This appears to be a common clinical sign, not only in individuals with simple $22 \mathrm{q} 13$ deletion but also in $\mathrm{r}(22)$ patients. Six subjects did not present any sign of hypotonia, and four of these had a deletion smaller than $310 \mathrm{~kb}$. In contrast, two patients with a large deletion encompassing $8 \mathrm{Mb}$ had very severe hypotonia. Thus hypotonia does not appear to be a constant clinical sign associated with the 22q13 deletions, particularly when these are of small size. Nevertheless, all patients with a deletion exceeding $4 \mathrm{Mb}$ had hypotonia, and its severity increased with the size of the deletion. 
Global developmental delay, particularly of motor milestones, was observed in all the patients of our series, although it can be mild in patients with small size deletions. This clinical feature clearly increased in severity in proportion to the size of the deletion, irrespective of the rearrangement involved.

Expressive speech delay was constant $(100 \%)$ in patients where this feature could be ascertained. It was always severe, and constituted the most characteristic clinical feature observed in our patients, regardless of the type of rearrangement. However, in our series, the correlation between the degree of severity and the size of the deletion was not evident, as severe language impairment was observed in patients with very small deletions.

Facial features were generally not severely dysmorphic, but large or dysplasic ears were frequently but not always present $(82 \%)$.

Like expressive speech delay, behavioural disorders were a constant clinical feature $(100 \%)$ in patients aged more than one year. These included hyperactivity, sleep troubles, aggressive outbursts, or confusional states. Nevertheless, owing to their reduced autonomy, patients with a large deletion appeared less severely affected by behavioural disorders than the others. It was noted that the severity of behavioural disorders increased with age, so that the personality of the patients appeared to change progressively. This observation was particularly evident in patients with cryptic 22q13 deletion, and there was no discrepancy related to the type of chromosomal anomaly.

Seizures were observed in only eight of the 33 patients $(24.2 \%)$. These were not correlated with the type of rearrangement or the size of the deletions, as they were present in patients with $0.9 \mathrm{Mb}$ and $7.2 \mathrm{Mb}$ deletions.

Finally, though the majority of our patients showed normal growth, there was a tendency to accelerated growth in those with simple deletions or translocations (37.5\%), and in contrast, a tendency to delayed growth in $\mathrm{r}(22)$ patients $(23.5 \%)$.

Overall our results showed a positive correlation between the severity of the phenotype and the size of the deletion for all types of deletion, regardless of their parental origin. In addition, we noted a clear evolution of the phenotype with age.

\section{DISCUSSION}

Our molecular characterisation of $3322 \mathrm{q} 13$ deletions, including both simple terminal deletions and $\mathrm{r}(22)$ chromosomes, allows us to establish and compare phenotypegenotype correlations for these two syndromes and to answer some questions about the mechanism of their formation.

\section{Is there any difference between the $r(22)$ and the $\operatorname{del}(22)(q 13)$ syndromes?}

We have shown that in patients with simple 22q13 deletion or $\mathrm{r}(22)$, the severity of the phenotype, and in particular the behavioural disorders, may increase with age. Consequently, any phenotype comparison should take into account the age of the patients, which previous studies did not. In contrast to earlier reports, our results show that clinical features are very similar in patients with simple 22q13 deletion and $\mathrm{r}(22)$ patients when they are within the same age bracket and have similarly sized deletions. This phenotypic similarity between the two syndromes is in agreement with the remarkable stability of the ring observed in metaphase in nearly all the $r(22)$ patients. Nevertheless, despite the stability observed in metaphase, micronuclei were present in cultures of all $\mathrm{r}(22)$ patients. Micronuclei are caused by the ring structure itself, which induces difficulties in sister chromatid separation at cell division, resulting in an increased rate of cell death. ${ }^{21}$ In support of this, we have demonstrated by FISH that the micronuclei contain the $\mathrm{r}(22)$. We may suppose that cell death associated with the ring structure itself is responsible for the growth failure present in several $r(22)$ patients, in contrast with the accelerated growth often observed in patients with simple $22 \mathrm{ql} 3$ deletion. In support of this hypothesis, patient 1 -who showed more severe growth failure than other $\mathrm{r}(22)$ patients-also had the most unstable ring, with $10 \%$ of abnormal cells. However, we cannot exclude the possibility that the variable phenotypes reported in $\mathrm{r}(22)$ patients in other studies are a consequence of destabilising structures in the ring, such as telomere repeats or strongly amplified rDNA sequences. None of these particularities was observed in our patients with $\mathrm{r}(22)$, as telomere repeats were absent and rDNA sequences discrete.

In cases where rig 22 is highly unstable, various additional clinical signs could be expected in the $\mathrm{r}(22)$ patients, which differentiate them from patients with simple 22q13 deletion. An increased number of cells with dicentric r(22) could result in some phenotypic features of "cat eye syndrome", 22 combining pre-auricular skin tags or pits with iris colobomata. In contrast, the presence of a large number of cells with loss of the $\mathrm{r}(22)$, resulting in loss of the NF2 gene and other tumour suppressor genes on chromosome 22, could increase the risk of developing neurofibromatosis ${ }^{23-26}$ and also tumours of the nervous system..$^{27-30}$

The $22 q 13$ deletions are most often paternal in origin The expression of the phenotype was not affected by parental origin of the deleted chromosome in either the 22q13 deletion syndrome or the $\mathrm{r}(22)$ syndrome. Nevertheless, we showed a strong excess of paternal origin of the 22q13 deletions for all classes of rearrangement. Such an excess was particularly evident for $\mathrm{r}(22)$ and for translocations involving an acrocentric short arm, but was also present for simple $22 \mathrm{q} 13$ deletions. In addition, this excess was observed to be stronger for small size deletions. This observation is consistent with the moderate increase in paternal origin observed in the simple $22 \mathrm{q} 13$ deletions of our series, as these are of large size. A preferential paternal origin of $22 \mathrm{q} 13$ deletions has not previously been reported, ${ }^{10}$ probably because of the small number of cases with molecular characterisation. Nevertheless, among the few de novo $22 \mathrm{q} 13$ deletions analysed in this way, seven were of paternal origin $^{1373132}$ and three were maternal in origin, ${ }^{145}$ which is consistent with our results. A high recombination frequency is known to be associated to subtelomeric regions both in male and female meioses. ${ }^{33-35}$ Interestingly, subtelomeric regions, particularly in $22 \mathrm{q}$, are enriched in dinucleotide (GT)n repeats, which can enhance the recombination frequency. ${ }^{36} 37$ This property of (GT)n repeats could result from their ability to bind the hsRad51 recombinase protein preferentially, ${ }^{38}{ }^{39}$ or to form Z-DNA. ${ }^{40}$ The enhanced recombination associated with $(\mathrm{GT}) \mathrm{n}$ repeats has been shown to be greater in males. ${ }^{36}{ }^{37}$ The reason for this increased recombination in males remains unknown, but could be related to differences between male and female meiosis. ${ }^{41}$ Finally, it is possible that the high recombination rate observed in the male subtelomeric $22 \mathrm{q}$ region could be the cause of an increased paternal origin of the 22q13 deletions observed in our series.

\section{Possible sequences favouring the occurrence of $22 q 13$} deletions

In our series, we have shown that several breakpoints were located in the same interval (PAC 402G1l-PAC 579N16), suggesting that there might be sequences in this interval that confer susceptibility to chromosome rearrangements. This interval of about $100 \mathrm{~kb}$, located between sequences AL022328 and AL096767, has not yet been sequenced ${ }^{18}$ 
(and data from the "UCSC genome browser"), and constitutes the most distal gap of the seven described in the $22 \mathrm{q}$ telomeric region. It has been suggested that such gaps in the sequence databases contain sequences that are unclonable with the available host-vector systems. $^{18}$ Interestingly, unclonable sequences have been shown to correlate with genomic instability, ${ }^{42}$ which may lead to the deletions observed within this region. Six other gaps are located in the subtelomeric $22 \mathrm{q}$ region, ${ }^{18}$ and these may also favour the occurrence of $22 \mathrm{q} 13$ deletions.

In our series, and in the literature, there is a relative high frequency of rings (22) and translocations which involve both the subtelomeric $22 \mathrm{q}$ region and the short arm of an acrocentric (22p or others). Moreover, in the present study, we have shown that the 22pll band is the most commonly involved at the breakpoints of the $\mathrm{r}(22)$. The pll band of acrocentric chromosomes contains several types of high copy number, tandemly repeated DNA, including satellites I, II, III, and $\beta$ satellite. ${ }^{43-46}$ We therefore searched for specific sequence homology between the $22 \mathrm{q}$ subtelomeric region and the various satellite DNAs from the $22 \mathrm{pll}$ band. We found the $\mathrm{G}+\mathrm{C}$ rich portion of the satellite I DNA sequence to be interesting, as it contains one Alu family member per repeat. ${ }^{47}$ Numerous Alu sequences are also present in the subtelomeric regions of chromosomes, ${ }^{48}$ and in particular in 22q. ${ }^{49}$ Interestingly, Alu elements are known to be the site of unequal recombination, ${ }^{50}$ leading to various cytogenetic alterations, including deletions, rings, or translocations.

Thus our study suggests that the particular sequence of the subtelomeric $22 \mathrm{q}$ region, enriched in numerous unclonable gaps, as well as Alu elements, could be the cause of the relative frequency of 22q13 deletions.

\section{The minimum critical region}

Two patients of our series have a similar $160 \mathrm{~kb}$ cryptic deletion, delineated by a breakpoint distal to the BAC 384D8, known to contain the ARSA gene. These patients, who presented mild global developmental delay and severe language impairment, are monosomic for a chromosome segment including only the ProSAP2/SHANK3, ACR, and RABL2B genes. This confirms that the minimum critical region for the $22 \mathrm{q} 13$ monosomy syndrome does not include the ARSA gene, and emphasises that a probe distal to ARSA must be used if all the 22q13 deletions are to be diagnosed. Among the three deleted genes, it has been suggested that ProSAP2/SHANK3 is involved in the severe language impairment that characterises the $22 \mathrm{q} 13$ deletion syndrome. ${ }^{11}{ }^{51}$ Indeed, ProSAP2/SHANK3 is preferentially expressed in the cortex and cerebellum ${ }^{52}$ and encodes a protein involved in the postsynaptic density of excitatory synapses. Moreover, the fact that behavioural disorders are present in both patients also suggests that the ProSAP2/SHANK3 gene could be involved in the appearance of this feature, which we have shown to be part of the phenotype that increases in severity with age.

\section{Conclusions}

Although the incidence of the deletion is not yet established, the increasing number of $22 \mathrm{q} 13$ deletions that have been reported recently indicates that these types of deletion may be occurring more often than previously thought. Therefore, any patient with mild global developmental delay, severe speech delay, and behavioural disorders-which may be moderate in young subjects—should be studied by FISH in order to search for a cryptic 22q13 deletion. Moreover, in order to prevent or slow down any aggravation of their behavioural disorders, health care provision should be adapted to the particular needs of these patients.

\section{ACKNOWLEDGEMENTS}

We are very grateful to the patients, their families, and the physicians who participated in this study, thereby making the data collection possible. The "Association pour la Recherche contre le Cancer "(ARC), the "Fondation pour la Recherche Médicale" (FRM), the Ministère de la Recherche (ACI Biologie du développement) are acknowledged for their financial support. JL is supported by a grant from the "Fondation Electricité de France" (EDF). We thanks Mike Mitchell for helpful discussion and reviewing of the text.

\section{Authors' affiliations}

J J Luciani, D Depetris, C Mignon-Ravix, M-G Mattei, Inserm U 491 Faculté de Médecine, Marseille, France

P de Mas, G Bourrouillou, Service de Génétique, CHU Purpan, Toulouse, France

A Bottani, Division de Génétique Médicale, Faculté de Médecine, Geneva, Switzerland

M Prieur, Service de Cytogénétique, Hôpital Necker-Enfants Malades, Paris, France

A Philippe, Unité de Génétique Clinique, Hôpital Necker-Enfants Malades

P Jonveaux, Laboratoire de Génétique, CHU Brabois, Vandoeuvre-lesNancy, France

B de Martinville, Laboratoire de Génétique Médicale, Hôpital Jeanne de Flandre, Lille, France

B Delobel, Laboratoire de Cytogénétique, Hôpital Saint-Antoine, Lille L Vallee, Service de Neurologie Infantile, Chru de Lille, Lille M-F Croquette, Alliance 22, Frelinghien, France

Correspondence to: Dr Marie-Geneviève Mattei, Inserm U 491, Faculté de Médecine, 27 Boulevard Jean Moulin, F-13385 Marseille, France; genevieve.mattei@medecine.univ-mrs.fr

\section{REFERENCES}

1 Flint J, Wilkie AO, Buckle VJ, et al. The detection of subtelomeric chromosomal rearrangements in idiopathic mental retardation. Nat Genet 1995;9:132-40.

2 Knight SJ, Flint J. Perfect endings: a review of subtelomeric probes and their use in clinical diagnosis. J Med Genet 2000;37:401-9.

3 Precht KS, Lese CM, Spiro RP, et al. Two 22q telomere deletions serendipitously detected by FISH. J Med Genet 1998;35:939-42.

4 Nesslinger NJ, Gorski JL, Kurczynski TW, et al. Clinical, cytogenetic, and molecular characterization of seven patients with deletions of chromosome 22q13.3 Am J Hum Genet 1994:54:464-72.

5 Doheny KF, McDermid HE, Harum K, et al. Cryptic terminal rearrangement of chromosome 22q13.32 detected by FISH in two unrelated patients. J Med Genet 1997:34:640-4.

6 Wong AC, Ning Y, Flint J, et al. Molecular characterization of a 130-kb terminal microdeletion at $22 \mathrm{q}$ in a child with mild mental retardation. Am J Hum Genet 1997;60:113-20.

7 Schröder K, Schuffenhaver S, Seidel H, et al. Deletion mapping by FISH with BACs in patients with partial monosomy 22q13. Hum Genet 1998; 102:557-61.

8 Praphanphoj V, Goodman BK, Thomas GH, et al. Cryptic subtelomeric translocations in the 22q13 deletion syndrome. J Med Genet 2000;37:58-61.

9 Prasad C, Prasad AN, Chodirker BN, et al. Genetic evaluation of pervasive developmental disorders: the terminal 22q13 deletion syndrome may represent a recognizable phenotype. Clin Genet 2000;57:103-9.

10 Phelan MC, Rogers RC, Saul RA, et al. 22q13 deletion syndrome. Am J Med Genet 2001;101:91-9.

11 Anderlid BM, Schoumans J, Anneren G, et al. FISH-mapping of a 100-kb terminal 22q13 deletion. Hum Genet 2002;1 10:439-43.

12 Lee KA, Kim SH, Lee MH, et al. Tandem translocation of chromosomes 22 and 15 with two preserved satellite stalk regions and deletion 22q13.3-qter. Am J Med Genet 2001;104:291-4.

13 Maclean JE, Teshima IE, Szatmari P, et al. Ring chromosome 22 and autism report and review. Am J Med Genet 2000;90:382-5.

14 De Mas $\mathbf{P}$, Chassaing N, Chaix Y, et al. Molecular characterisation of a ring chromosome 22 in a patient with severe language delay: a contribution to the refinement of the subtelomeric $22 q$ deletion syndrome. J Med Genet 2002;39:e17.

15 Johnson A, Minoshima S, Asakawa S, et al. A 1.5-Mb contig within the cat eye syndrome critical region at human chromosome $22 q 11.2$. Genomics 1999;57:306-9.

16 Lansdorp PM, Verwoerd NP, van de Rijke FM, et al. Heterogeneity in telomere length of human chromosomes. Hum Mol Genet 1996;5:685-91.

17 Levy N, Navarro A, Depetris D, et al. Localization of ribosomal genes in human spermatogonia by fluorescent in situ hybridization and confocal microscopy. Cytogenet Cell Genet 1996;73:290-4.

18 Dunham I, Shimizu N, Roe BA, et al. The DNA sequence of human chromosome 22. Nature 1999;402:489-95. 
19 Schinzel AA, Basaran S, Bernasconi F, et al. Maternal uniparental disomy 22 has no impact on the phenotype. Am J Hum Genet 1994;54:21-4.

20 Nakamura $\mathrm{H}$, Itoyama T, Niikawa N, et al. No parental origin bias for the rearranged chromosomes in myeloid leukemias associated with $t(9 ; 22)$, $t(8 ; 21)$ and $t(15 ; 17)$. Leuk Res 1998;22:793-6.

21 Kosztolanyi G. Does "ring syndrome" exist? An analysis of 207 case reports on patients with a ring autosome. Hum Genet 1987;75:174-9.

22 Frizzley JK, Stephan MJ, Lamb AN, et al. Ring 22 duplication/deletion mosaicism: clinical, cytogenetic, and molecular characterisation. J Med Genet 1999;36:237-41.

23 Duncan AM, Partington MW, Soudek D. Neurofibromatosis in a man with a ring 22: in situ hybridization studies. Cancer Genet Cytogenet 1987;25:169-74.

24 Taalman RD, Weemaes CM, Hustinx TW, et al. Chromosome studies in IgAdeficient patients. Clin Genet 1987;32:81-7.

25 Tommerup N, Warburg M, Gieselmann V, et al. Ring chromosome 22 and neurofibromatosis. Clin Genet 1992;42:171-7.

26 Kehrer-Sawatzki H, Udart M, Krone W, et al. Mutational analysis and expression studies of the neurofibromatosis type 2 (NF2) gene in a patient with a ring chromosome 22 and NF2. Hum Genet 1997; 100:67-74.

27 Arinami T, Kondo I, Hamaguchi $\mathrm{H}$, et al. Multifocal meningiomas in a patient with a constitutional ring chromosome 22. J Med Genet 1986;23:178-80.

28 Petrella $\mathrm{R}$, Levine S, Wilmot PL, et al. Multiple meningiomas in a patient with constitutional ring chromosome 22. Am J Med Genet 1993;47:184-6.

29 Rubio A. March 1997 - 4 year old girl with ring chromosome 22 and brain tumor. Brain Pathol 1997;7:1027-8.

30 Korones DN, Meyers SP, Rubio A, et al. A 4-year-old girl with a ventriculoperitoneal shunt metastasis of a central nervous system atypical teratoid/rhabdoid tumor. Med Pediatr Oncol 1999:32:389-91.

31 Phelan MC, Thomas GR, Saul RA, et al. Cytogenetic, biochemical, and molecular analyses of a $22 q 13$ deletion. Am J Med Genet 1992;43:872-6.

32 De Vries BB, Bitner-Glindzicz M, Knight SJ, et al. A boy with a submicroscopic 22qter deletion, general overgrowth and features suggestive of FG syndrome. Clin Genet 2000;58:483-7.

33 Collins A, Frezal J, Teague J, et al. A metric map of humans: 23,500 loci in 850 bands. Proc Natl Acad Sci USA 1996:93:14771-5.

34 Wintle RF, Nygaard TG, Herbrick JA, et al. Genetic polymorphism and recombination in the subtelomeric region of chromosome 14q. Genomics 1998;40:409-14.

35 Brennan MD, Neibergs HL, Phillips K, et al. Polymorphic markers for the arylsulfatase A gene reveal a greatly expanded meiotic map for the human 22q telomeric region. Genomics 2000;63:430-2.

36 Majewski J, OHt J. GT repeats are associated with recombination on human chromosome 22. Genome Res 2000;10:1108-14.
37 Tapper WJ, Ke X, Morton NE, et al. Recombination, interference and sequence: comparison of chromosomes 21 and 22. Ann Hum Genet 2002;66:75-86.

38 Tracy RB, Baumohl JK, Kowalczykowski SC. The preference for GT-rich DNA by the yeast Rad51 protein defines a set of universal pairing sequences. Genes Dev 1997;11:3423-31.

39 Biet E, Sun J, Dutreix M. Conserved sequence preference in DNA binding among recombination proteins: an effect of ssDNA secondary structure. Nucleic Acids Res 1999;27:596-600.

40 Wahls WP, Wallace $\amalg$, Moore PD. The Z-DNA motif $d(T G) 30$ promotes reception of information during gene conversion events while stimulating homologous recombination in human cells in culture. Mol Cell Biol 1990;10:785-93.

41 Ashley T. Mammalian meiotic recombination: a reexamination. Hum Genet 1994:94:587-93.

42 Razin SV, loudinkova ES, Trifonov EN, et al. Non-clonability correlates with genomic instability: a case study of a unique DNA region. $J \mathrm{Mol}$ Biol 2001;307:481-6

43 Agresti A, Rainaldi G, Lobbiani A, et al. Chromosomal location by in situ hybridization of the human Sau3A family of DNA repeats. Hum Genet 1987;75:326-32

44 Tagarro I, Fernandez-Peralta AM, Gonzalez-Aguilera JJ. Chromosomal localization of human satellites 2 and 3 by a FISH method using oligonucleotides as probes. Hum Genet 1994;93:383-8.

45 Tagarro I, Wiegant J, Raap AK, et al. Assignment of human satellite 1 DNA as revealed by fluorescent in situ hybridization with oligonucleotides. Hum Genet 1994;93:125-8.

46 Greig GM, Willard HF. Beta satellite DNA: characterization and localization of two subfamilies from the distal and proximal short arms of the human acrocentric chromosomes. Genomics 1992;12:573-80.

47 Frommer M, Prosser J, Vincent PC. Human satellite I sequences include a male specific $2.47 \mathrm{~kb}$ tandemly repeated unit containing one Alu family member per repeat. Nucleic Acids Res 1984;12:2887-900.

48 Rosenberg M, Hui L, Ma J, et al. Characterization of short tandem repeats from thirty-one human telomeres. Genome Res 1997:7:917-23.

49 Chen C, Gentles AJ, Jurka J, et al. Genes, pseudogenes, and Alu sequence organization across human chromosomes 21 and 22. Proc Natl Acad Sci USA 2002;99:2930-5.

50 Deininger PL, Batzer MA. Alu repeats and human disease. Mol Genet Metab 1999:67:183-93

51 Bonaglia MC, Giorda R, Borgatti R, et al. Disruption of the ProSAP2 gene in a $t(12 ; 22)(q 24.1 ; q 13.3)$ is associated with the $22 q 13.3$ deletion syndrome. Am J Hum Genet 2001;69:261-8.

52 Boeckers TM, Bockmann J, Kreutz MR, et al. ProSAP/Shank proteins - a family of higher order organizing molecules of the postsynaptic density with an emerging role in human neurological disease. J Neurochem 2002;81:903-10. 